MUZIKOLOŠKI ZBORNIK - MUSICOLOGICAL ANNUAL VI, LJUBLJANA 1970

\title{
AKUSTIČNA ŠTUDIJA DRUMELJCE
}

\author{
Bruno Ravnikar (Ljubljana)
}

Drumeljca je preprost glasbeni inštrument, ki je bil močno razširjen tako med nerazvitimi kot razvitimi ljudstvi. V najbolj preprosti obliki je drumeljca izdelana iz kosa bambusa, $v$ katerega je vrezan prosto nihajoči jeziček. Med igranjem je naslonjena na zgornje in spodnje zobe tako, da predstavlja ustna votlina resonator izza jezička drumeljce. $Z$ brenkanjem jezička ustvarjamo ton, ki se $\mathrm{v}$ ustni votlini še posebej ojači. Nihajoči jeziček in zrak v ustni votlini predstavljata potemtakem dva sklopljena nihajna sistema. Kasnejše izvedbe drumeljce so kovinske. Pri njih je pritrjen prožen in jeklen jeziček na kovinski okvir v obliki epolete. Brenkanju namenjen konec jezička je pravokotno zapognjen in predstavlja vzvod, ki olajšuje brenkanje.

S spreminjanjem ustne votline dosežemo modulacijo proizvedenega tona. Močno odprta ustna votlina povzroča nastanek nizkih tonov, medtem ko nam daje ozko stisnjena ustna votlina visoke tone.

V Evropi je spadala drumeljca $\mathrm{k}$ tako imenovani »musici irregularis«, t. $\mathrm{j}$. h glasbi preprostega ljudstva, beračev in otrok. Iz 16. stoletja je znana slika Hansa Burgmaira »Zmagoslavje cesarja Maksimiljana«, na kateri je upodobljeno igranje drumeljce na vozu za norce. V začetku 19. stoletja je postala drumeljca virtuozni inštrument in iz tega časa imamo podatke o umetnikih, ki so uporabljali do 16 drumeljc, da bi iz njihovih alikvotnih tonö̌ lahko ustvarili uporabno lestvico. $\mathrm{Na}$ alpskem področju je postala drumeljca priljubljen pripomoček fantov pri vasovanju, medtem ko jo po letu 1830 izpodrinejo orglice. Sachs ugotavlja, da ga menda ni inštrumenta, ki bi imel pri različnih ljudstvih tako različna in pomanjkljiva imena. ${ }^{1}$ Nemci ga imenujejo »Maultrommel«, Angleži »Jew's harp«, ${ }^{2}$ Italijani »Spassapensieri«, Švedi »Mungiga«, Rusi »Vargan « in Francozi »Rebute«.

Delovanje drumeljce opisujejo mnogi znani avtorji več ali manj enako. Mednje moramo prišteti mimo že imenovanega $\mathrm{Sachsa}^{3}$ še Bainesa $^{4}$ in Klimo.

1 Sachs C., Handbuch der Musikinstrumentenkunde, Leipzig 1930, 64.

2 Angleži so prvotni naziv »jaw's harp« (čeljustna harfa) iz neznanega razloga spremenili v »jew's harp« (židovska harfa).

3 Ibid., 62.

4 Baines A., Musical Instruments Through the Ages, Penguin Books 1966, 39.

5 Klima J., Spielanleitung für die Maultrommel, München 1967, 2. 
Njihova razlaga trdi, da ojačimo $v$ ustni votlini nekatere višje harmonske tone nihajočega jezička, medtem ko osnovnega tona ne moremo proizvajati. Tonski niz, ki odgovarja višjim harmonskim tonom od četrtega dalje, bi bil za drumeljco $\mathrm{z}$ osnovnim tonom $\mathrm{C}$ naslednji: $\mathrm{c}^{1}, \mathrm{e}^{1}, \mathrm{~g}^{1}, \mathrm{~b}^{1}, \mathrm{c}^{2}, \mathrm{~d}^{2}$ itd. Podoben niz predstavljajo višji harmonski toni trobil. Iz te razlage vidimo, da ne moremo vzbujati vseh tonov harmonične lestvice, kar nekako omejuje uporabo tega inštrumenta. Celotno diatonsko lestvico dobimo šele od osmega harmonskega tona dalje, to pa je zopet mogoče le pri večjih drumljah z nižjo osnovno frekvenco.

Klima navaja v svojem delu nekaj notnih primerov za igranje $\mathrm{z}$ drumeljco, ${ }^{6}$ vendar obsegajo izbrane melodije proti pričakovanju vse stopnje diatonske lestvice. Nadaljnje razočaranje prinese poskus dvoglasnega igranja $\mathrm{z}$ dvema drumeljcama. Ako želimo zaigrati neko melodijo v vzporednih tercah, nam bo to uspelo le takrat, kadar bosta razmaknjeni tudi osnovni frekvenci v intervalu terce. To pa pomeni, da ima osnovna frekvenca drumeljce vendar važno vlogo, čeprav zatrjujejo že omenjeni avtorji, da je ni mogoče vzbuditi. In še $\mathrm{v}$ eno protislovje pademo, če želimo zaigrati na drumeljci glissando. To nam uspe brez truda, čeprav lahko vzbujamo po objavljenih opisih le določene tone diatonske lestvice.

Vsa ta dejstva postavljajo dosedanje razlage $\mathrm{v}$ dvomljivo luč in terjajo zadovoljiv odgovor vsaj na zastavljena tri vprašanja. Sledeča razlaga bo skušala dati primerno pojasnilo, pokazala pa bo tudi, da slonijo vsi dosedanji opisi na napačnih osnovah.

Drumeljca predstavlja dva sklopljena nihajna sistema. Prvi sistem je prosto nihajoči jeziček, ki ima aktivno vlogo, drugi sistem pa je pasivni ustni resonațor, ki ojačuje določene frekvence nihajočega jezička. Za nihajoči jeziček pravokotnega preseka velja diferencialna enačba

$$
\frac{\delta^{2} y}{\delta t^{2}}+\frac{E \cdot d^{2}}{12 \varrho} \cdot \frac{\delta^{4} y}{\delta x^{4}}=0
$$

Tu je »y« odmik jezička iz mirovne lege, »t« čas, »X« koordinata vzdolž jezička, »E« elastični modul jezička (za jeklo $22.000 \mathrm{kp} / \mathrm{mm}^{2}$ ), 》d « debelina jezička in "Q gostota jezička (za jeklo $7900 \mathrm{~kg} /{ }^{3}$ ). Iz robnih pogojev za jeziček, ki je na enem koncu vpet, na drugem pa prosto niha, dobimo končno enačbo

$\mathrm{Tu}$ je

$$
\cos \mathrm{w} \cdot \cosh \mathrm{w}=-1
$$

$$
w^{2}=\frac{4 \pi f \cdot 1^{2}}{d} \sqrt{\frac{3 \varrho}{E}}
$$

in pomeni »1《 dolžino jezička.

Zgornja transcendentna enačba ima korene $\mathrm{w}_{1}=1,875, \mathrm{w}_{2}=4,695$, $\mathrm{w}_{3}=7,854, \mathrm{w}_{4}=10,99, \mathrm{w}_{5}-14,14$ itd. Že na prvi pogled vidimo, da vrednosti korenov ne sledijo harmonskemu zaporedju. Praviloma torej tudi

6 Ibid., 7 ss. 
alikvotni toni drumeljce ne morejo predstavljati harmonskega niza, ampak nepravilni neharmonski niz! Če vstavimo izračunane vrednosti v obrazec za frekvenco, dobimo

$$
f=\frac{w^{2} \cdot d}{4 \pi 1^{2}} \sqrt{\frac{E}{3 \varrho}}
$$

in razmerja frekvenc alikvotnih tonov

$$
\begin{aligned}
& \mathrm{f}_{1}=0,1616 \cdot \frac{\mathrm{d}}{1^{2}} \sqrt{\frac{E}{\varrho}} \\
& \mathrm{f}_{2}=6,26 \mathrm{f}_{1} \\
& \mathrm{f}_{3}=17,53 \mathrm{f}_{1} \\
& \mathrm{f}_{4}=34,36 \mathrm{f}_{1} \\
& \mathrm{f}_{5}=56,6 \mathrm{f}_{1} \\
& \mathrm{f}_{6}=84,5 \mathrm{f}_{1}
\end{aligned}
$$

Že niz prvih šestih alikvotnih tonov obsega več kot šest oktav. Iz izračunanih vrednosti vidimo, da imamo prvi alikvotni ton in obenem tudi osnovni ton na začetku prve oktave. Drugi alikvotni ton je v sredini tretje oktave, tretji alikvotni ton $\mathrm{v}$ začetku pete oktave, četrti alikvotni ton $\mathrm{v}$ začetku šeste oktave, peti alikvotni ton $\mathrm{v}$ sredini šeste oktave itd. Niz alikvontih tonov je tako redek, da $z$ njimi ne bi mogli izvajati nobene uporabne melodije. Tako je ovržena trditev že omenjenih avtorjev, da uporabljamo pri igranju na drumeljco alikvotne tone od četrtega harmonskega dalje.

Pojavi se vprašanje, kako potemtakem sploh igramo na drumeljco? Mehanska slika se $\mathrm{z}$ našim računom ni prav nič spremenila. Jeziček je še vedno aktivni del, ustna votlina pa resonator, ki ojačuje določeno frekvenco. Frekvenca igranih tonov na drumeljci je odvisna od resonančne frekvence ustne votline. To frekvenco si lahko ocenimo po Helmholtzu ${ }^{7}$ s pomočjo izpeljanega obrazca

$$
f=c \sqrt{\frac{r}{2 \pi^{2} V}}
$$

kjer je »c« hitrost zvoka v zraku, »r« povprečen polmer odprtine ust, kadar so ustnice naslonjene na drumeljco in $\gg V$ « prostornina ustne votline. Meritve so pokazale, da je pri moškem največja prostornina ustne votline približno $120 \mathrm{~cm}^{3}$, najmanjša pa $20 \mathrm{~cm}^{3}$. Pri povprečnem polmeru odprtine ust $\mathrm{r}=0,5 \mathrm{~cm}$ dobimo za ustrezni resonančni frekvenci vrednost $\mathrm{f}_{\min }=540 \mathrm{~Hz}$ in $f_{\max }=1080 \mathrm{~Hz}$, kar ustreza resničnemu obsegu drumeljce, ki je približno ena oktava. $Z$ drumeljco lahko torej proizvajamo tone od cca $500 \mathrm{~Hz}$ do $1000 \mathrm{~Hz}$. Iz našega računa pa sledi, da v to področje lahko tudi ne pade noben alikvotni ton drumeljce in igranje bi bilo nemogoče. Navidezno zmedo lahko 602 .

${ }^{7}$ Helmholtz H. v., Die Lehre von den Tonempfindungen, Brauschweig 1913, 
takoj odpravimo, če se spomnimo vsiljenega nihanja. Nihajoči jeziček je razmeroma močno dušen, zato mu ni težko nihati s frekvenco, ki mu jo vsiljuje resonator ustne votline. Alikvotni ton jezička, ki je frekvenčno najbližji resonančni frekvenci ustne votline, se premakne $\mathrm{k}$ tej frekvenci, $\mathrm{s}$ to frekvenco vsiljeno niha, ustna votlina pa to frekvenco še posebej primerno ojači. Pri tem ne smemo zanemariti nižjih alikvotnih tonov, zlasti ne osnovnega. Ta zveni stalno skupaj $\mathrm{z}$ modulirano melodijo in predstavlja bordunsko spremljavo.

$\mathrm{Z}$ opisano razlago lahko sedaj odgovorimo na zastavljena vprašanja. Dvoglasno igranje $\mathrm{z}$ dvema drumeljcama je resnično mogoče samo takrat, kadar je med obema drumeljcama nek konsonančen interval, npr. velika terca, saj se osnovni ton drumeljce stalno oglaša in ne izgine, kot to trdijo Sachs, Baines in Klima. Nadalje lahko zaigramo na drumeljci poljuben ton katerekoli lestvice $\mathrm{v}$ obsegu od $500 \mathrm{~Hz}$ do $1000 \mathrm{~Hz}$, pri tem pa ne smemo pozabiti, da se bo stalno oglašal tudi bordunski ton osnovne frekvence. In končno sledi iz naše razlage, da lahko glede na značaj vsiljenega nihanja drumeljce zaigramo poljuben glissando $\mathrm{v}$ omenjenem frekvenčnem območju.

Ta razlaga vsekakor ne bi bila popolna, če bi slonela le na teoretični razlagi. Zato ji moramo dodati še rezultate meritev, katere je $\mathrm{v}$ ta namen ljubeznivo izvedel dr. Graf s sonagrafom. ${ }^{8}$ Meritev se nanaša na drumeljco, katere osnovno frekvenco smo predhodno ocenili na $50 \mathrm{~Hz}$. Po naših ugotovitvah bi se morali pri vzbujanju te drumeljce oglasiti še naslednji alikvotni toni

$$
\mathrm{f}_{2}=313 \mathrm{~Hz} \quad \mathrm{f}_{3}=877 \mathrm{~Hz} \quad \mathrm{f}_{4}=1718 \mathrm{~Hz} \text { itd. }
$$

Posnet je bil glissando $\mathrm{z}$ drumeljco in analiziran. Sonagram je pokazal, da niha drumeljca stalno $\mathrm{z}$ osnovno frekvenco $50 \mathrm{~Hz}$. Tej frekvenci se pridružuje drugi alikvotni ton $s$ frekvenco $270 \mathrm{~Hz}$, medtem ko tretji alikvotni ton ne niha $\mathrm{s}$ stalno frekvenco, ampak se njegova frekvenca spreminja $\mathrm{z}$ vsiljeno frekvenco ustne votline od $500 \mathrm{~Hz}$ do $900 \mathrm{~Hz}$. Četrti alikvotni ton ni več tako izrazit in je njegova frekvenca okrog $1300 \mathrm{~Hz}$. Izmerjene vrednosti odstopajo od izračunanih zato, ker nismo upoštevali mase zapognjenega dela jezička, vendar je ujemanje kljub temu dokaj dobro. Drugi alikvotni ton odstopa za $16 \%$, tretji se popolnoma podredi vsiljeni frekvenci, četrti pa ponovno odstopa za $32 \%$.

Sonagram nam prinese še en dokaz o pravilnosti naših trditev. V primeru, da bi imeli $v$ frekvenčnem območju od $500 \mathrm{~Hz}$ do $1000 \mathrm{~Hz}$ resnično opraviti $\mathrm{Z}$ nizom harmonskih alikvotnih tonov, bi se to prav gotovo pokazalo $\mathrm{v}$ posameznih resonančnih maksimumih registrirane amplitude našega glissanda. Ti pa popolnoma izostanejo in amplituda enakomerno pada brez sledi o kakršnih koli vmesnih resonančnih mestih.

Teoretične študije in meritve na drumeljci so pokazale, da moramo drumeljco uvrstiti med inštrumente s prosto nihajočim jezičkom in redko posejanimi alikvotnimi toni. Melodijo izvajamo tako, da s spreminjanjem resonančne frekvence ustne votline spravimo $\mathrm{k}$ vsiljenemu nihanju najbližji ali-

\footnotetext{
8 Graf W., Die musikalische Klangforschung, Karlsruhe 1969, 23.
} 


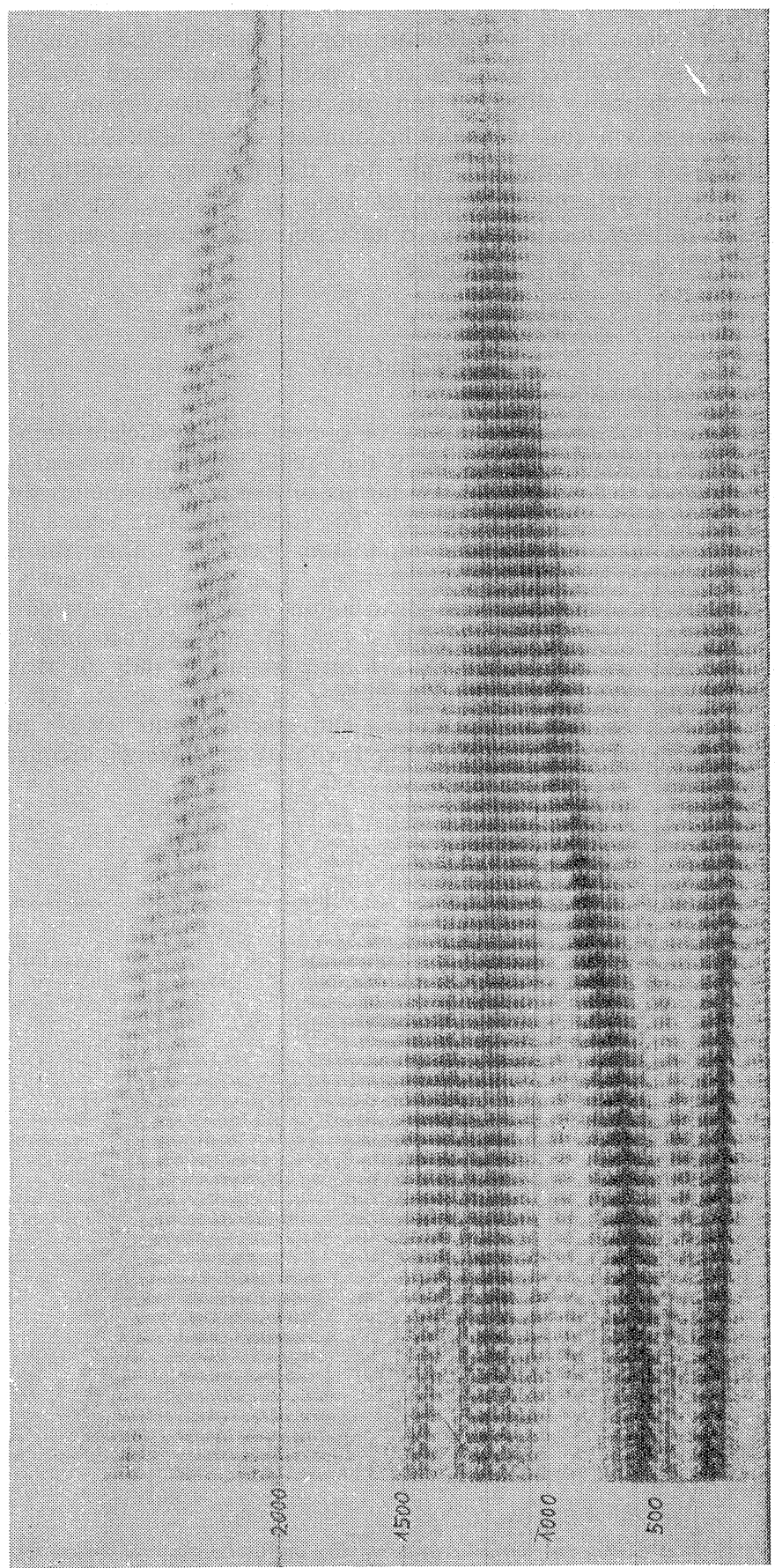


kvotni ton. Frekvenčni spekter tega nihanja je zvezen in ne kaže nobenih prednostnih frekvenc, zato je praktično mogoče vzbuditi vsak ton $v$ frekvenčnem območju od $500 \mathrm{~Hz}$ do $1000 \mathrm{~Hz}$. Poleg moduliranega tona, ki je pri večjih drumeljcah tretji alikvotni ton, pri manjših pa verjetno že drugi, se stalno oglaša osnovni ton $\mathrm{v}$ obliki bordunske spremljave. Nič slabši ni pri večjih drumeljcah tudi drugi alikvotni ton, ki prav tako spremlja modulirano melodijo. Dodatni prijemi, ki jih uporabljajo pri igranju, kot npr. sunkovito vdihavanje in izdihavanje, ne vplivajo na višino vzbujanega tona in rezultatov naše analize $v$ ničemer ne spreminjajo.

\section{SUMMARY}

Descriptions of the Jew's harp up to the present are insufficient from the standpoint of physics. Therefore the author of the article indicates the need for a more exhaustive study of this instrument. By means of higher mathematics the series of overtones of the Jew's harp is calculated. The sound structure agrees closely with the measurements taken on the sonograph. Both methods confirm the assumption of the author that the series of the overtones of the Jew's harp is not a harmonic one, but it presents a non-harmonic distribution with rather scattered overtones. Therefore when playing on this instrument we do not produce individual overtones but we cause a vibration with a forced frequency only of that overtone which is the nearest to the resonance frequency of the oral cavaty. The frequency spectrum of the Jew's harp is continuous and reaches from $500 \mathrm{~Hz}$ to $1000 \mathrm{~Hz}$. Besides the modulated frequency a bourdon with its fundamental frequency simultaneously vibrates. 